Journal of Economics and Behavioral Studies

Vol. 4, No. 11, pp. 660-670, Nov 2012 (ISSN: 2220-6140)

\title{
A Review on Moral Development, Multicultural Experiences and Conflict Handling Styles of Purchasing Professionals
}

\author{
Yi-Hui Ho*, Chieh-Yu Lin \\ Chang Jung Christian University, Taiwan \\ *vicky@mail.cjcu.edu.tw
}

\begin{abstract}
Conflicts between the buyers and sellers are often inevitable during the progress of purchasing activities. It is essential to understand the conflict handling styles of purchasing professionals for those who want to build reciprocal buyer-supplier relationships. Nevertheless, only little attention was paid on the study of purchasing professionals' conflict handling styles. While ethical purchasing is often considered essential in maintaining the relationships with suppliers, purchasing professionals' moral development may influence their conflict handling. Furthermore, because of the growing numbers of global suppliers, purchasing professionals who are often exposed to multicultural occasions are expected to be capable to communicate and negotiate with their suppliers to prevent possible conflicts. There is no research analyzing the association between multicultural experiences, moral development and conflict handling styles of purchasing professionals. Accordingly, based on a review of related literature, this paper attempts to explore the impact of multicultural experiences and moral development on conflict handling styles of purchasing professionals, and provide some research suggestions. The findings of this paper can contribute to the research on conflict handling of purchasing professionals.
\end{abstract}

Keywords: Conflict handling styles, moral development, multicultural experiences, purchasing professionals

\section{Introduction}

The purchasing function of a company plays an important role in maintaining effective business operations while high-quality raw materials and supplies available on a timely basis are required for global competitive success. Purchasing professionals have to manage purchasing function effectively to keep long-term relationships with suppliers and achieve the company's strategic objectives (Bell, Oppenheimer \& Bastien, 2002; Razzaque \& Hwee, 2002). During the progress of purchasing activities, conflicts are usually inevitable. The conflicts may exist between buyers and sellers or between departments within the firm. Some empirical studies on the impact of conflict management on inter-firm relationships (Plank, Reid \& Newell, 2007; Tangpong \& Ro, 2009) and job performance (Chan, Huang \& Ng, 2008; Song, Dyer \& Thieme, 2006) suggests that purchasing professionals' conflict handling will influence firm's purchasing performance and buyer-supplier relationships. Therefore, it is important to study-purchasing professionals' conflict handling styles. Conflict handling styles are the "patterned responses or clusters of behavior that people use in conflict" (Hocker \& Wilmot, 1985), and are associated with an individual's cultural traits, personality, and the situation in which the conflict occurs. The choice of conflict handling styles is associated with several individual characteristics. An individual's gender, culture, moral development, experiences, and social value orientation may influence her or his choice of conflict handling styles (Ogilvie \& Kidder, 2008). Several researchers have explored the relationships between individual characteristics and conflict handling styles. However, most of prior studies explored students' conflict handling styles (e.g. Balay, 2007; Chow \& Ding., 2002), and some analyzed managers' conflict handling styles (e.g. Lian \& Tui, 2008). Only a few studies (Day, Michaels \& Perdue, 1988; Hagen, Kedia \& Oubre., 2003) investigated the associations between purchasing professionals' some demographic variables and conflict handling styles. They did not analyze the influences of moral development and multicultural experiences on conflict handling styles for purchasing professionals. Moral development and multicultural experiences are two important individual characteristics in current business environment confronted by purchasing professionals. As the importance of the purchasing function in businesses increases, there has been a concurrent increase in the importance of purchasing ethics. Ethical behavior within the purchasing function not only maintains reliable relationships with their suppliers but also satisfies their customers. Purchasing professionals, who are responsible for the purchasing duties, are expected to serve as a communication link to the external business community, and to develop and maintain long-term relationships with the firm's vendors. 
Emergence of purchasing as a strategic function has not only broadened the scope of purchasing, it has also changed the responsibilities of the purchasing managers by empowering them to spend large sums of money in procuring goods and services (Razzaque \& Hwee, 2002). However, this has also presented them with an array of ethical dilemmas involving questionable purchasing practices. With the business environment becoming increasingly competitive in recent years, purchasing professionals continue to face a challenging ethical environment. Their ethical judgment on such dilemmas has become an issue of concern (Bell et al., 2002; Spekman \& Carraway, 2006). Individual moral development is central to the decisions people make about whether or not to behave ethically (Kohlberg, 1969; Rest, 1986). Purchasing professionals with different levels of moral development may exhibit different behavior. One person may approach the purchasing decision focused on personal gain at the potential expense of the group, while another may approach the same decision focused on the good of the group at the potential expense of the individual (Ho, 2012). However, little attention was paid on the relationship between moral development and conflict handling styles. Chow and Ding (2002) compared business students in Hong Kong and China, and found positive association between moral development and the use of integrating style to handle conflicts. Rahim, Buntzman and White (1999) found positive relationship between the post-conventional people and their tendency of using the integrating style to resolve conflict for business students. There is no research analyzing the associations between moral development and conflict handling styles for purchasing professionals. In addition, multicultural experiences are usually recognized as a benefit for executives and employees in international business. With increasing globalization, multicultural experiences are crucial to purchasing managers because they will have more occasions to interact with individuals from different countries and cultures. Individuals who possess multicultural experiences, such as working or doing business with foreigners and studying abroad, may be more likely to cope with international business conflicts (Leonidou, Katsikeas \& Hadjimarcou, 2002).

In addition, multicultural experiences may also influence individual decision-making and behavior $(\mathrm{Ng}$, Linn \& Asang, 2009). Deficient multicultural experiences may negatively influence individual's cross-cultural adaption and therefore result in unsuccessful international assignments (Townsend \& Wan, 2007). Lack of multicultural experiences will also bring about difficulties of building and maintaining relationships with stakeholders from different cultural backgrounds, including foreign suppliers (Skarmeas \& Robson, 2008). While embracing sufficient multicultural experiences is beneficial for purchasing professionals, it is therefore imperative to study the impact of multicultural experiences on conflict handling styles. Nevertheless, a review of literature reveals that there is no research investigating the association between multicultural experiences and conflict handling styles. To fill the research gap, the main purpose of this paper is to explore the impact of moral development and multicultural experiences on purchasing professionals' conflict handling styles based on a review of related literature. Conflict handling is inevitable for purchasing professionals when facing purchasing issues. When a purchasing conflict happens, tension occurs between the purchasing professional's duty to both the employer and the supplier. Each purchasing professional may possibly handle the conflict in different ways, and therefore lead to different outcomes. Handling conflict and maintain good buyer-seller relationships has become essential for purchasing professionals. Understanding the way purchasing professionals handling the conflict will be helpful for those who want to build a close buyer-supplier relationship.

\section{Conflict Handling}

Conflict handling is one of the most essential issues in the conflict literature. There seems to be no completed definition of conflict as it concludes a variety of disciplines, such as psychology, sociology, anthropology, and communication (Saphiro \& Kulik, 2004). The only consensus about the nature of conflict is that it appears when people with different needs or goals, or perceive that they are being impeded by others in satisfying and achieving these needs or goals. To a preferred or balanced outcome, conflict handling is therefore the necessary process to resolve conflict among interest groups (Rahim, 1983). Conflict handling styles reveal an individual's cultural traits, personality, and the situation in which the conflict occurs. Hocker and Wilmot (1985) define conflict-handling styles as "patterned responses or clusters of behavior that people use in conflict" (Hocker \& Wilmot, 1985). A number of styles of conflict handling have been proposed to explain the communication behavior during conflict. Black and Mouton (1964) are perhaps the first researchers proposing the dual dimension typology about the negotiators' concerns: concern for production, and concern for people. They classified five types of handling interpersonal conflicts, including compromising, smoothing, forcing, withdrawal, and confrontation. Since then, this dual concern model, with opposing notions of concern for self and others, has become the 
prototype of the successive research on conflict handling styles. For instance, Thomas and Kilmann (1974) suggest the two-dimension taxonomy of conflict handling modes to interpret how conflict-handling styles affect personal and group dynamics. These two dimensions are assertiveness (i.e. concern for self) and cooperativeness (i.e. concern for other) which classified a person's conflict handling styles into five categories: avoiding, accommodating, competing, compromising, and collaborating. Rahim and Bonoma (1979) catalog two dimensions "concern for self" and "concern for others" with five styles of conflict handling to explain the types of handling interpersonal conflict. These five styles are integrating, obliging, dominating, avoiding, and compromising (Rahim, 1983). Figure 1 is the combined figure of the model proposed by Thomas and Kilmann (1974) and Rahim and Bonoma (1979).

Figure 1: Dual-dimension model of conflict handling styles

\begin{tabular}{|c|c|c|}
\hline $\begin{array}{l}\text { High } \\
\text { Concern for others }\end{array}$ & $\begin{array}{l}\text { Obliging } \\
\text { (Accommodating) }\end{array}$ & $\begin{array}{r}\text { Integrating } \\
\text { (Collaborating) }\end{array}$ \\
\hline \multirow[t]{2}{*}{ Low } & Avoiding & $\begin{array}{r}\text { Dominating } \\
\text { (Competing) }\end{array}$ \\
\hline & Low & High \\
\hline
\end{tabular}

(Assertiveness)

A person who is both low on concerning self and others is an avoider, meaning unassertiveness and uncooperativeness in dealing with conflict. He or she may use withdrawal tactics or put off conflict issues, or even does not recognize that there is any dispute. In the contrast, an integrating (or collaborating) person is both high on concerning self and others when dealing with conflict. Integrating is traditionally considered the most beneficial way to resolve conflict (Browaeys \& Price, 2008). This type of people is more likely to work together actively to get a win-win solution to satisfy the needs of both sides. For those who are both in the middle of concerning self and others are likely to compromise between the needs of both sides. This type of people may make a mutually acceptable solution so that the conflict can be solved. Someone who is high on concerning self and low on concerning others is dominating (or competing), pursuing more on self interest rather than others' interest. Contrast to the competing style, if a person is high on concerning others and low on concerning self is accommodating (or obliging), meaning the propensity to satisfy the needs of others. The collaborating style is usually considered the preferable way among these five styles of conflict handling (Browaeys \& Price, 2008; Brahnam et al., 2005; Lovelace, Shapiro, \& Weingart, 2001). This win-win strategy implies the consideration of mutual gains for both parties and thus is likely to be used in business contexts for mutual benefit (Brahnam, et al., 2005). Nevertheless, Rahim, Garrett and Buntzman (1992) argue that each style of handling interpersonal conflict is appropriate if it is used to achieve an organization's proper end. No single conflict handling style is more suitable than others are. Therefore, several studies suggest situational approach that the selection of better conflict handling styles depends on the conflict situation (Deleure, 2005; Goodwin, 2002; Rahim, 2002). The dual-dimension model is the major model used for research on conflict handlings though some researchers doubt whether this dual-dimension model can be applied appropriately to the increasing complexity of modern business world disputes (Saphiro \& Kulik, 2004). Leung, Koch and Lu (2002) indicate that the dual concern model mainly concentrates on instrumentality, as conflict behaviors are driven by concerns for the outcome of the conflict, i.e. self or others. Consequently, they incorporate the concept of harmony and suggest that it is effective for conflict avoidance. Regardless the argument, the dual-dimension model is still the most commonly used model for research on conflict management and handling (Brahnam et al, 2005; Chan et al., 2008; Kray \& Haselhuhn, 2007; Moriizumi \& Takai, 2010; Tangpong \& Ro, 2009). Based on the dual-dimension model, some instruments have been developed to assess individual conflict handling styles; for example, the Conflict Measurement Survey developed by Kilmann and Thomas (1977), the Rahim Organizational Conflict 
Inventory (ROCI-II) developed by Rahim (1983), and the Dutch Test for Conflict Handling (DUTCH) developed by Van de Vliert (1997). Each instrument has its advantages and disadvantages. Among these instruments, the ROCI-II is the most widely used in the conflict literature (De Dreu, Evers, Beersma, Kluwer \& Nauta, 2001; Ogilvie \& Kidder, 2008). The ROCI-II instrument can measure five conflict handling styles, and comes in three forms, one concerned with conflicts with one's supervisor, one concerned with conflicts with one's peer, and one concerned with one's subordinates. Several studies have used the ROCI-II to measure individual conflict handling styles (e.g., Chan et al., 2008; Dee, Henkin \& Holman, 2004; Rahim, Antonioni \& Psenicka, 2001).

Conflict Handling Styles of Purchasing Professionals: While facing a conflict situation, the choice of conflict handling styles is associated with individual characteristics. In addition to the characteristics of the conflict situation, an individual's gender, culture, moral development, working experiences, education, emotional intelligence, and social value orientation may influence her or his choice of conflict handling styles (Ogilvie \& Kidder, 2008). Several researchers have explored the relationships between individual characteristics and conflict handling styles (e.g., Balay, 2007; Chow \& Ding, 2002; Hagen et al., 2003; Ogilvie \& Kidder, 2008 ;). However, most of prior studies explored students' conflict handling styles (e.g. Balay, 2007; Rahim et al., 1999), and some analyzed managers' conflict handling styles (e.g. Lian \& Tui, 2008; Portello \& Long, 1994). Only Day et al. (1988) and Hagen et al. (2003) explored the relationships between purchasing mangers' conflict handling styles and respondent demographic variables. In a survey of members of American National Association of Purchasing Management, Day et al. (1988) found that most purchasing professionals are predisposed to utilize collaborating and compromising behaviors across situations of conflict and their conflict handling styles are associated with some demographic variables. Also taking members of the same association as samples, Hagen et al. (2003) found that the collaborating style predominate among purchasing professionals, and conflict handling styles are associated with personal characteristics including age, education, experience, income, gender, and marital status. These two studies only investigated the associations between purchasing professionals' demographic variables and conflict handling styles. They did not analyze the influences of moral development and multicultural experiences on conflict handling styles of purchasing professionals.

\section{Moral Development}

The theory of cognitive moral development proposed by Kohlberg (1969) has been widely used in understanding the reasons that people use in making moral judgments. Kohlberg (1969) defines moral reasoning as the judgment about right and wrong; moral development is the level of maturity of moral reasoning. He also defines a subject's level of moral reasoning as the reasoning used to defend one's position when faced with an ethical dilemma. From this viewpoint, Kohlberg thinks that this would be more important than the actual choice made, since the choices people make in such a dilemma are not always clearly and indisputably right. Kohlberg (1969) argues that as individuals mature, so too does their ethical judgment. Kohlberg (1969) proposes that as people mature and acquire more education and experience, their moral reasoning develops along with a well-defined sequence of stages. According to Kohlberg's cognitive moral development theory, cognitive moral development is the extent to which consideration should ideally be given to resolve a particular ethical dilemma, and it describes the sophisticated cognitive moral structure that an individual is potentially capable of utilizing (Thorne, 2000). Kohlberg divides moral development into three major levels and six stages: The pre-conventional level focuses on the consequences of decisions for the self; the conventional level deal with the in-group of family, friends, and peers; and the post-conventional level focuses on principles for humanity in general. Each successive stage requires thinking that is more complex and involves the individual's consideration of an increasingly wide range of persons and institutions. Kohlberg argues that individuals respond differently to ethical issues in accordance with their stage of moral development (Jones, Massey, \& Thorne, 2002). The six stages of Kohlberg's cognitive moral development are shown in Table1.

\section{Table 1: Kohlberg's Six Stages of Cognitive Moral Development Theory}

\section{Pre-conventional Level - focus on self}

Stage 1 Obedience: You do what you are told primarily to avoid punishment.

Stage 2 Instrumental egotism and simple exchange: Let us make a deal or only consider the costs and/or benefits to one. 
Conventional Level - focus on relationship with others

Stage 3 Interpersonal concordance: Be considerate, nice and kind and you will get along with people. Focus is on cooperation with those in your environment.

Stage 4 Law and duty to the social order: Everyone in society is obligated to and is protected by the law. Focus is on cooperation with society in general.

Post-conventional Level - focus on personally held principles of justice

Stage 5 Societal consensus: You are obligated by whatever arrangements are agreed to and by due process and procedure. Focus is on fairness of the law or rule as determined by equity and equality in the process of developing the rule.

Stage 6 Non-arbitrary social cooperation: Rational and impartial people would view cooperation as moral. Focus is on fairness of the law or rules derived from general principles of just and right as determined by rational people.

Note: Adapted from Development in judging moral issues, by J. R. Rest, 1979, Minneapolis, MN: University of Minnesota Press.

A review of the moral cognition/action empirical literature conducted by Blasi (1980) concludes that individuals at a higher moral stage are more likely to resist the pressure of conforming to the judgments of others. The review also concludes that while there is a statistical relationship between moral development and moral action, moral development cannot totally explain ethical/unethical behavior. For example, individuals at a higher stage are not always more honest and altruistic, and post-conventional level individuals are not always more likely to resist social pressure to conform in moral action. Accordingly, a "higher stage of moral development is a necessary but not sufficient condition for moral behavior such as honesty, altruism, and resistance to temptation" (Trevino, 1986). Up to the present, Kohlberg's cognitive moral development theory is the most widely used theory in analyzing individuals' moral development, though some researchers argue that it has its limits (Trevino, 1986). Still, Kohlberg's theory seems to be the dominant theoretical framework for research of moral development, and Trevino (1992) suggests that Kohlberg's theory can be used as a framework to study the impact of societal culture on business ethics. Kohlberg's theory of cognitive moral development has also been used in studying business ethics. According to Kohlberg's theory, moral development is the level of moral reasoning a person uses to defend his or her position when faced with a moral issue. It refers to the consideration of what should ideally be done to resolve a particular ethical dilemma. To measure an individual's cognitive moral development, Moral Judgment Interview (MJI) developed by Kohlberg (Colby \& Kohlberg, 1987) and the Defining Issues Test (DIT) developed by Rest (1979) are two different approaches that have traditionally been employed by researchers in moral development research. Although Kohlberg's cognitive moral development theory is the basis of the DIT, the DIT is used more frequently than the MJI to assess the moral development stages of people. The DIT is a short, objective instrument that is practical for large-scale research (Narváez \& Bock, 2002). The DIT measures the ethical understanding of subjects, and does not necessarily require that they possess strong verbal and oral skills; it measures recognition knowledge, a type of tacit knowledge rather than explicit verbal knowledge. Narváez and Bock (2002) indicate that the DIT is a better measurement for knowing the levels of moral development for most people than the MJI; the DIT not only finds more empirical evidence about Kohlberg's post-conventional levels than Kohlberg's MJI, but the MJI also finds little evidence for stage five ethical reasoning and none for stage six. Therefore, for practical consideration, the DIT is frequently used for measuring moral development.

\section{The Association between Moral Development and Conflict handling Style}

Rahim et al. (1992) suggest that selecting specific conflict handling styles (for example, dominating) may include ethical component in nature. Ethics and conflict handling are related elements in successful business management (Rahim et al, 1999). As a person is moral development is a critical component of 
his/her ethical action (Rest, 1986), it is believed that ethical issues are usually accompanied with conflict interests. Making ethical decisions often implies handling conflict of each interest group. Individuals may develop a more complex and mature ethical reasoning only through conflict. Therefore, it is speculated that there is an association between moral development and conflict handling styles. However, up to now, only Rahim et al. (1999) and Chow and Ding (2002) study the association between moral development and conflict handling styles, and both indicate the relationship between high-level moral development and the adoption of integrating handling style for business students. Rahim et al., (1999) conduct a research, which takes employed business students as the subject to explore the relationship between stages of moral development and interpersonal conflict handling styles in organizations. They use the Defining Issues Test (DIT) (Rest, 1986), and the Rahim Organizational Conflict Inventory-II (ROCI-II) (Rahim, 1983). The findings of the study indicate that students at the post-conventional level of moral development attempt to use more integrating and less dominating and avoiding styles than those at conventional level. The conventional-level students use more integrating and less dominating and avoiding styles than pre-conventional students. The higher the level of moral development, the more possibilities to use integrating style to handle conflict. Moreover, conventional-level students tend to use more compromising style than their post-conventional and pre-conventional counterparts do. As to the obliging style, the findings of the study do not suggest significant differences across these three stages of moral development. Chow and Ding (2002) explore the association between moral judgment and conflict handling styles of undergraduate business students and MBA students in Hong Kong and China. They also use the Defining Issues Test (DIT) (Rest, 1986), and Rahim's organizational conflict inventory-II (ROCI-II) (Rahim, 1983). The result indicates that there is a significant positive association between stages of moral development and the preference usage of integrating style of conflict handling, but do not find significant correlation between the DIT scores and the other styles of conflict handling. They also find significant difference in the DIT scores between their Hong Kong and China samples though both sides share a common Chinese cultural heritage. These two studies only choose business students as research subjects. Ethics issues and conflict situations in business profession might be more complicated than what students face on campus. No evidence can generalize their research results to purchasing contexts. There is still no research analyzing the association between moral development and conflict handling styles of purchasing professionals. Based on a review of related literature, this paper suggests that a purchasing professional's moral development will influence his/her conflict handling styles, and accordingly proposed the following research proposition:

P1: A purchasing professional's conflict handling style is associated with his/her moral development.

Multicultural Experience: Due to the increasing global business, enriching multicultural experiences is crucial for business professionals because these people have more occasions to interact with others from different cultures at present or in the future. Graf (2004) address that foreign language competence, adaptability, and respect for cultural differences were rated as crucial skills for international managers, along with intercultural communication skills and sensitivity. These intercultural competences are positively associated with an individual's multicultural experiences (Shaftel, Shaftel, \& Ahluwalia, 2007). People with multicultural experience are found to develop the intrinsic appreciation of other cultural groups, which will better benefit their adaption to multicultural environment (Lee \& Davis III, 2000). In a study of Australian business students, Townsend and Wan (2007) found a positive association between socio-cultural adaptation and multicultural experience. Multicultural experience has multi-faced nature that varies along several dimensions (Takeuchi et al., 2005). Accordingly, various categorizations of multicultural experiences have been proposed in the literature. For instance, Selmer (2002) takes participants' past multicultural experiences to investigate the relationship between multicultural experiences and the adjustment. Takeuchi et al. (2005) extend Selmer's (2002) study and build a model of multicultural experiences on expatriates' adjustment by differentiating a person's multicultural experiences into current and past ones. Their model divided past experiences into two dimensions: domain and cultural specificity. The domain dimension includes work and non-work domains, and the dimension of cultural specificity consists of culture-specific and culture-general component. In addition, the numbers and length of previous multicultural experiences are both considered in their study. Townsend and Wan (2007) define multicultural experience as "the combination of time of study and quality of interaction with people from different cultures"; time of study refers to the length of time spent in a multicultural environment, and quality refers to the depth of interactions.

In general, there is no major instrument measuring an individual's multicultural experiences in the literature. Endicott, Bock, \& Narvaez (2003) evaluate students' multicultural experiences in the areas of 
multicultural attitudes, breadth of multicultural activities, and depth of multicultural activities. The instrument they used is then revised to a shorter version, contains two main subscales: the multicultural experience subscale and the multicultural desire subscale. This updated version is called the Multicultural Experience Questionnaire (MEQ), which is developed for measuring multicultural experience and attitudes (Narvaez, Endicott \& Hill, 2003). The multicultural experience domain implies the number of multicultural experiences a person has had; for instance, how many times the respondents travel abroad, language they can speak, countries they currently correspond with, how often they work with different ethnic people, pay attention to news about the world, enjoy media and art from different culture, and so on. In terms of the multicultural desire domain, it represents a person's effort or desire to increase his/her multicultural experiences; for example, the willingness to travel outside the home country, make friends from different cultural and ethnic background, get to know different people and understand their viewpoint, discuss issues of discrimination racism and oppression, explore one's own prejudices and biases. Individual with higher MEQ scores are more open-minded, less being jingoism, and more likely to perceive discrimination and sexism as common issues.

The Association between Multicultural Experience and Conflict Handling Style: Jassawalla, Truglia, and Garvey (2004) reported that interpersonal conflict is a key factor in the early termination or failure of international assignments for managers. Interpersonal conflict occurred in three general categories related to differing perceptions of task urgency and time use, negative stereotypes of Americans, and different value systems resulting from local laws and ethical practices. When these circumstances were, successfully navigated, expatriate managers reported that they depended on abilities and attributes such as a sense of adventure, good listening skills, open-mindedness, flexibility, willingness to learn on the job, learning the host language, patience, and optimism. Individuals who possess multicultural experiences, such as working or doing business with foreigners and studying abroad, are more likely to cope with international business conflicts (Leonidou, Katsikeas \& Hadjimarcou, 2002). Mintu-Wimsatt and Gassenheimer (2004) suggest that salespeople's problem-solving approach is to some extent associated with their international sales experiences. In the past, the impact of one's multicultural experiences has gain considerably attention. Multicultural experiences may influence individual decision-making and behavior (Mintu-Wimsatt \& Gassenheimer, 2004; Ng, Linn \& Asang, 2009). However, research on the association between multicultural experiences and conflict handling styles still cannot be found in the literature. Neither is the research focusing on multicultural experiences of purchasing professionals. Some previous studies have measured the impact of multicultural experiences on changes in students' self-confidence (Ishino et al., 1999), social-cultural adaptations (Townsend \& Wan, 2007), campus belongings (Lee \& Davis III, 2000), foreign language ability and extroversion (Isoda, 1999). Furthermore, Berger (2000) found that students who joined in multicultural activities and interacted with different racial-ethnic groups are more likely to take part in community service during college. Students participating in off-campus learning programs such as studying in foreign countries demonstrated significant growth in principled moral reasoning during college (McNeel, 1994). Interaction with diverse individuals with divergent intellectual and social perspectives tends to enhance growth in principled moral reasoning (Derryberry \& Thoma, 2000). In addition, Brislin (1990) indicates that U.S. students may develop problem-solving skills and interdisciplinary thinking by interacting with international students. Taylor (1994) found that multicultural experiences in developing countries can help medical students enhance their openness to different kinds of people, become more flexible and self-reliance, and understand the cultural relativity. Kauffman (1983) suggests that experiences of studying abroad contribute to students' interests in others' welfare. It also helps motivate students' reflective thought, which increase their ability to think in ways that are more complex.

Thomlinson (1991) also found that study-abroad experiences benefit students' ability to handle new and different environment as well as their personal independence. Vincenti (2001) suggests that benefit of international or intercultural experiences consists of personal warmth and openness, enhanced interest in others' welfare and appreciation of other's different values, increased idealism and service orientation, increased understanding and acceptance of other culture, and respectful of people as well. Endicott et al. (2003) explored the relationships between individuals' multicultural experiences and moral development. They found that college students who have more multicultural experiences demonstrated higher levels of moral development. There is a significantly positive association between multicultural activities and the post-conventional level of moral development. To foster moral development, Endicott et al. (2003) suggest that students should spend more efforts in multicultural reading, speaking, working, friendships, courses and other activities. Endicott et al.'s (2003) study focuses on the impact of multicultural 
experiences on moral development of college students in general. Individuals with experiences of involving in multicultural activities may be more able to be aware of the relativism of personal values, which are helpful for one's post-conventional ethical developing and the dealing with conflict. Accordingly, it is reasonable to expect that multicultural experiences may somehow influence a person's moral development as well as conflict handling styles. As moral development is part of one's ethical decision-making process, and is possibly impact on the conflict handling styles, it is expected that multicultural experiences will affect on purchasing professionals' conflict handling styles. However, there is no research on the associations between multicultural experiences and conflict handling styles for purchasing professionals. There is still a research gap on the study of the impact of multicultural experiences on conflict handling styles of purchasing professionals. Based on a review of related literature, this paper suggests that a purchasing professional's multicultural experiences will influence his/her conflict handling styles, and accordingly proposed the following research proposition:

P2: A purchasing professional's conflict handling style is associated with his/her multicultural experiences.

\section{Summary}

Conflict handling is inevitable for purchasing professionals when facing purchasing issues. When a purchasing conflict happens, tension occurs between the purchasing professional's duty to both the employer and the supplier. Each purchasing professional may possibly handle the conflict in different ways, and therefore lead to different outcomes. Effective conflict handling and managing is crucial for the purchasing activities in business for maintaining the buyer-supplier relationships. Therefore, it is necessary to understand the conflict handling styles of purchasing professional. As the occurrence of conflict is often associated with ethical issues, purchasing professionals with different levels of moral development might reveal different styles in handling conflict. However, there is still a research gap on the study of the impact of moral development on conflict handling styles for purchasing professional. In addition, there is no research that investigates the influence of purchasing professionals' multicultural experiences on conflict handling styles. As a result, the paper explores the associations between purchasing professionals' multicultural experiences and moral development and their conflict handling styles. Based on a review of related research, two research propositions are proposed in the study: (1) $A$ purchasing professional's conflict handling style is associated with his/her moral development; and (2) A purchasing professional's conflict handling style is associated with his/her multicultural experiences. Because the study only analyzes the association between moral development, multicultural experiences and conflict handling styles of purchasing professionals by reviewing related literature, future research can conduct an empirical study on of the impact of moral development and multicultural experiences on conflict handling styles of purchasing professionals.

Acknowledgement: We are grateful to the National Science Council of the Republic of China for the financial support of this work under the grant NSC 100-2410-H-309-002.

\section{References}

Balay, R. (2007). Predicting conflict management based on organizational commitment and selected demographic variables. Asia Pacific Education Review, 8(2), 321-336.

Bell, G. G., Oppenheimer, R. J. \& Bastien, A. (2002). Trust deterioration in an international buyer-supplier relationship. Journal of Business Ethics, 36(1/2), 65-78.

Berger, J. B. (2000). Organizational behavior at college and student outcomes: A new perspective on college impact. Review of Higher Education, 23(2), 177-198.

Black, R. \& Mouton, J. (1964). The Managerial Grid: The Key to Leadership Excellence. Houston: Gulf Publishing.

Blasi, A. (1980). Bridging moral cognition and moral action: A critical review of the literature. Psychological Bulletin, 88(1), 1-45.

Brahnam, S. D., Margavio, T. M., Hignite, M. A., Barrier, T. B. \& Chin, J. M. (2005). A gender-based categorization for conflict resolution. Journal of Management Development, 24(3), 197-208.

Brislin, R. W. (1990). Applied cross-cultural psychology (14) Cross-cultural research and methodology series, Newbury Park, CA: Sage.

Browaeys M. J. \& Price R. (2008). Understanding cross-cultural management. UK: Prentice Hall.

Chan, K. W., Huang, X. \& Ng, P. M. (2008). Managers' conflict management styles and employee attitudinal outcomes: The mediating role of trust. Asia Pacific Journal of Management, 25, 277-295. 
Chow, I. H. S. \& Ding, D. Z. Q. (2002). Moral judgment and conflict handling styles among Chinese in Hong Kong and PRC. Journal of Management Development, 21(9), 666-679.

Colby, A. \& Kohlberg, L. (1987). The measurement of moral judgment. New York, NY: Cambridge University Press.

Day, R. L., Michaels, R. E. \& Perdue, B. C. (1988). How buyers handle conflicts. Industrial Marketing Management, 17(2), 153-160.

De-Dreu, C. K. W., Evers, A., Beersma, B., Kluwer, E. S. \& Nauta, A. (2001). A theory-based measure of conflict management strategies in the workplace. Journal of Organizational Behavior, 22, 645-668.

Dee, J. R., Henkin, A. B. \& Holman, F. B. (2004). Reconciling differences: Conflict management strategies of catholic college and university presidents. Higher Education, 47, 177-196.

Deleure, H. (2005). Conflict resolution mechanisms, trust and perception of conflict in contractual agreement. Journal of General Management, 30(4), 11-26.

Derryberry, W. \& Thoma, S. (2000). The friendship effect: Its role in the development of moral thinking in students. About Campus, 5(2), 13-18.

Endicott, L., Bock, T. \& Narvaez, D. (2003). Moral reasoning, intercultural development, and multicultural experiences: Relations and cognitive underpinnings. International Journal of Intercultural Relations, 27(4), 403-419.

Goodwin, J. (2002). Auditors' conflict management styles: An exploratory study. Abacus, 38(3), 378-405.

Graf, A. (2004). Expatriate selection: An empirical study identifying significant skill profiles. Thunderbird International Business Review, 46, 667-685.

Hagen, A., Kedia, S. \& Oubre, D. (2003). Negotiating styles among American purchasing managers in the $21^{\text {st }}$ century: Revisited. Journal of Business and Economics Research, 1(8), 57-69.

Ho, Y. I. (2012). A review of research on ethical decision-making of purchasing professionals. Information Management and Business Review, 4(2), 72-78.

Hocker, J. L. \& Wilmo, W. W. (1985). Interpersonal Conflict. IA: William C. Brown.

Ingulsrud, J. E., Kai, K., Kadowaki, S., Kurobane, S. \& Shiobara, M. (2002). The assessment of cross-cultural experience: measuring awareness through critical text analysis. International Journal of Intercultural Relations, 26, 473-491.

Ishino, H., Masaki, M., Visgatis, B. \& Kimura, S. (1999). Tanki kaigai kenshu no motarasu mono 〔How short-term overseas study effects students ]. The Language Teacher, 23(6), 37-42.

Isoda, T. (1999). A study of personality change and English proficiency: A report on Japanese college students in a one-month English intensive program in America. Annual Review of English Learning and Teaching, 4, 51-62.

Jassawalla, A., Truglia, C. \& Garvey, J. (2004). Cross-cultural conflict and expatriate manager adjustment: An exploratory study. Management Decision, 42, 837-849.

Jones, J., Massey, D. W. \& Thorne, L. (2002). A review and synthesis of the empirical research on the ethical dimension of accountants' professional judgment. Paper presented at the meeting of American Accounting Association, Professionalism and Ethics Symposium, San Antonio, TX.

Kauffman, N. L. (1983). The impact of study abroad on personality change. Unpublished doctoral dissertation, Indiana University, Bloomington.

Kilmann, R. H. \& Thomas, K. W. (1977). Developing a forced choice measure of conflict handling behavior: The Mode instrument. Educational and Psychological Measurement, 37(2), 309-325.

Kohlberg, L. (1969). Stage and sequence: The cognitive developmental approach to socialization. In D. A. Goslin (Ed.), Handbook of socialization theory and research. (347-480). Chicago: Rand-McNally.

Kray, L. \& Haselhuhn, M. P. (2007). Implicit negotiation beliefs and performance: Experimental and longitudinal evidence. Journal of Personality and Social Psychology, 93(1), 49-64.

Lee, R. M. \& Davis III, C. (2000). Cultural orientation, past multicultural experience, and a sense of belonging on campus for Asian American college students. Journal of College Students Development, 41(1), 110-115.

Leonidou, L. C., Katsikeas, C. S. \& Hadjimarcou, J. (2002). Executive insights: Building successful export business relationships: A behavioral perspective. Journal of International Marketing, 10(3), 96-115.

Leonidou, L. C., Katsikeas, C. S. \& Hadjimarcou, J. (2002). Executive insights: Building successful export business relationships: A behavioral perspective. Journal of International Marketing, 10(3), 96-115.

Leung, K., Koch, P. T. \& Lu, L. (2002). A dualistic model of harmony and its implications for conflict management in Asia. Asia Pacific Journal of Management, 19, 201-220.

Lian, L. K. \& Tui, L. G. (2008). Effects of individual characteristics and organizational context on superiors 
use of conflict styles and subordinates satisfaction with supervision. Asian Academy of Management Journal, 13(1), 37-62.

Lovelace, K., Shapiro, D. L. \& Weingart, L. R. (2001). Maximizing cross-functional new product teams' innovativeness and constraint adherence: A conflict communications perspective. Academy of Management Journal, 44(4), 779-793.

McNeel, S. P. (1994). College teaching and student moral development. In J. R. Rest \& D. Narvaez (Eds.), Moral development in the professions: Psychology and applied ethics (27-49). Hillsdale, NJ: Lawrence Erlbaum Associates.

Mintu-Wimsatt, A. \& Gassenheimer, J. B. (2004). The problem solving approach of international salespeople: The experience effect. Journal of Personal Selling \& Sales Management, 24(1), 19-25.

Moriizumi, A. \& Takai, J. (2010). The relationships between Japanese interpersonal conflict styles and their language expressions. The Journal of Social Psychology, 150(5), 520-539

Narváez, D. \& Bock, T. (2002). Moral schemas and tacit judgment or how the defining issues test is supported by cognitive science. Journal of Moral Education, 31(3), 297-314.

Ng, K. Y., Linn, V. D. \& Asang, S. A. (2009). From experience to experiential learning: Cultural intelligence as a learning capability for global leader development. Academy of Management Learning and Education, 8(4), 511-526.

Ogilvie, J. R. \& Kidder, D. L. (2008). What about negotiator styles? International Journal of Conflict Management, 19(2), 132-147.

Plank, R. E., Reid, D. A. \& Newell, S. (2007). The impact of affective and cognitive social conflict in business-to-business buyer-seller relationships: A comparison of new versus ongoing buyer-seller relationships. Journal of Business-to-Business Marketing, 14(2), 41-72.

Portello, J. Y. \& Long, B. C. (1994). Gender role orientation ethical and interpersonal conflicts, and conflict handling styles of female managers. Sex Roles, 31(11/12), 683-701.

Rahim, M. A. (1983). A measure of styles of handling interpersonal conflict. Academy of Management Journal, 26(2), 368-376.

Rahim, M. A. (2002). Toward a theory of managing organizational conflict. International Journal of Conflict Management, 13(3), 206-225.

Rahim, M. A. \& Bonoma, T. V. (1979). Managing organizational conflict: A model for diagnosis and intervention. Psychological Report, 44, 1323-1344.

Rahim, M. A., Antonioni, D. \& Psenicka, C. (2001). A structural equations model of leader power, subordinates styles of handling conflict, and job performance. The International Journal of Conflict Management. 12(3), 191-211.

Rahim, M. A., Buntzman, G. F. \& White, D. (1999). An empirical study of the stages of moral development and conflict managing styles. The International Journal of Conflict Management, 10(2), 154-171.

Rahim, M. A., Garrett, J. E. \& Buntzman, G. F. (1992). Ethics of Managing Interpersonal Conflict in Organizations. Journal of Business Ethics, 11(5-6), 423-432.

Razzaque, M. A. \& Hwee, T. P. (2002). Ethics and purchasing dilemma: A Singaporean view. Journal of Business Ethics, 35(4), 307-326.

Rest, J. R. (1979). Development in judging moral issues. Minneapolis, MN: University of Minnesota Press.

Rest, J. R. (1986). Moral development: Advances in research and theory. New York, NY: Praeger Publishers.

Saphiro, D. L. \& Kulik, C. T. (2004). Resolving disputes between faceless disputants: New challenges for conflict management theory. In Gelfand, M. J. \& Brett, J. M. (eds.). The Handbook of Negotiation and Culture. Stanford, CA: Stanford Business Books.

Selmer, J. (2002). Practice makes perfect? International experience and expatriate adjustment. Management International Review, 42, 71-87.

Shaftel, J., Shaftel, T. \& Ahluwalia, R. (2007). International educational experience and intercultural competence. International Journal of Business \& Economics, 6(1), 25-34.

Skarmeas, D. \& Robson, M. J. (2008). Determinants of relationship quality in importer-exporter relationships. British Journal of Management, 19(2), 171-184.

Song, M., Dyer, B. \& Thieme, R. J. (2006). Conflict management and innovation performance: An integrated contingency perspective. Journal of Marketing Science, 34(3), 341-356.

Spekman, R. E. \& Carraway, R. (2006). Making the transition to collaborative buyer-seller relationships: An emerging framework. Industrial Marketing Management, 35(1), 10-19.

Takeuchi, R., Tesluk, P. E., Yun, S. \& Lepak, D. P. (2005). An integrative view of international experience. Academy of Management Journal, 48(1), 85-100.

Tangpong, C. \& Ro, Y. K. (2009). The role of agent negotiation behaviors in buyer-supplier relationships. Journal of Managerial Issues, 21(1), 58-79. 
Taylor, C. E. (1994). International experience and idealism in medical education. Academic Medicine, 69(8), 631-634.

Thomas, K. W. \& Kilmann, R. H. (1974). Thomas-Kilmann Conflict Mode Instrument. Tuxedo, NY: Xicom.

Thomlinson, T. D. (1991). Effects of a study-abroad program on university students: Toward a predictive theory of intercultural contact. Paper presented at the Eighth Annual Intercultural and Communication Conference, Miami.

Thorne, L. (2000). The development of two measures to assess accountants' prescriptive and deliberative moral reasoning. Behavioral Research in Accounting, 12, 139-169.

Townsend, P. \& Wan, C. (2007). The impact of multicultural experience in the development of socio-cultural adaptation for international business students. International Journal of Educational Management, 21(3), 194-212.

Townsend, P. \& Wan, C. (2007). The impact of multicultural experience in the development of socio-cultural adaptation for international business students. International Journal of Educational Management, 21(3), 194-212.

Trevino, L. K. (1986). Ethical decision-making in organizations: A person-situation interactionist model. Academy of Management Review, 11(3), 601-617.

Trevino, L. K. (1992). Moral reasoning and business ethics: Implications for research, education, and management. Journal of Business Ethics, 11(5-6), 445-459.

Van de Vliert, E. (1997). Complex Interpersonal Conflict Behavior. London: Psychology Press.

Vincenti, V. B. (2001). Exploration of the relationship between international experiences and the interdisciplinary work of university faculty. Journal of Studies in International Education, 5(42), 42-63. 